\title{
UNREPRESENTED NATIONS AND PEOPLES ORGANIZATION (UNPO)
}

UNPO is an international organization created by nations and peoples around the world who are not represented in the world's principal international organizations, such as the UN. Founded in 1991, UNPO now has 53 members representing over $100 \mathrm{~m}$. people worldwide.

Membership. Open to all nations and peoples unrepresented, subject to adherence to the five principles which form the basis of UNPO's charter: equal right to selfdetermination of all nations and peoples; adherence to internationally accepted human rights standards; to the principles of democracy; promotion of non-violence; and protection of the environment. Applicants must show that they constitute a 'nation or people' as defined in the Covenant.

Functions and Activities. UNPO offers an international forum for occupied nations, indigenous peoples, minorities and oppressed majorities, who struggle to regain their lost countries, preserve their cultural identities, protect their basic human and economic rights, and safeguard their environment.

It does not represent those peoples; rather it assists and empowers them to represent themselves more effectively. To this end, it provides professional services and facilities as well as education and training in the fields of diplomacy, human rights law, democratic processes, conflict resolution, and environmental protection. Members, private foundations and voluntary contributions fund the Organization.

In total six former members of UNPO (Armenia, Belau, East Timor, Estonia, Georgia and Latvia) subsequently achieved full independence and gained representation in the UN. Belau is now called Palau. Current members Bougainville and Kosovo are progressively achieving self-determination.

Headquarters: 40A Javastraat, NL-2585 AP The Hague, Netherlands.

Website: http://www.unpo.org

General Secretary: Marino Busdachin.

Publication. UNPO News (quarterly).

\section{INTERNATIONAL ORGANIZATION FOR MIGRATION (IOM)}

Established in Brussels in 1951 to help solve European population and refugee problems through migration, and to stimulate the creation of new economic opportunities in countries lacking certain manpower. IOM is committed to the principle that humane and orderly migration benefits migrants and society.

Members (102 as of Nov. 2003). Albania, Algeria, Angola, Argentina, Armenia, Australia, Austria, Azerbaijan, Bangladesh, Belgium, Belize, Benin, Bolivia, Bulgaria, Burkina Faso, Cambodia, Canada, Cape Verde, Chile, Colombia, Congo (Democratic Republic of), Congo (Republic of), Costa Rica, Côte d'Ivoire, Croatia, Cyprus, Czech Republic, Denmark, Dominican Republic, Ecuador, Egypt, El Salvador, Finland, France, Gambia, Georgia, Germany, Greece, Guatemala, Guinea, Guinea-Bissau, Haiti, Honduras, Hungary, Iran, Ireland, Israel, Italy, Japan, Jordan, Kazakhstan, Kenya, South Korea, Kyrgyzstan, Latvia, Liberia, Lithuania, Luxembourg, Madagascar, Mali, Malta, Mauritania, Mexico, Moldova, Morocco, Netherlands, New Zealand, Nicaragua, Nigeria, Norway, Pakistan, Panama, Paraguay, Peru, Philippines, Poland, Portugal, Romania, Rwanda, Senegal, Serbia and Montenegro, Sierra Leone, Slovakia, Slovenia, South Africa, Sri Lanka, Sudan, Sweden, Switzerland, Tajikistan, United Republic of Tanzania, Thailand, Tunisia, Uganda, Ukraine, UK, USA, Uruguay, Venezuela, Yemen, Zambia and Zimbabwe. 33 governments and a large number of government agencies and NGOs have observer status. 